\title{
Use of a Coordinated Social Media Strategy to Improve Dissemination of Research and Collect Solutions Related to Workforce Gender Equity
}

\author{
Kelly A. Cawcutt, MD, MS, FACP, Lillian M. Erdahl, MD, FACS, ${ }^{2}$ Meridith J. Englander, MD, FSIR, ${ }^{3}$ \\ Diane M. Radford, MD, FACS, FRCSEd, ${ }^{4-6}$ Amy S. Oxentenko, MD, FACP, FACG, AGAF, ${ }^{7}$ Linda Girgis, MD, \\ FAAFP, ${ }^{8}$ Lindsey L. Migliore, DO, ${ }^{9}$ Julie A. Poorman, $\mathrm{PhD},{ }^{10,11}$ and Julie K. Silver, MD ${ }^{10-13}$
}

\begin{abstract}
Background: To increase awareness, search for solutions, and drive change, disparity-related research needs to be strategically disseminated. This study aimed to quantify whether a social media strategy could: (1) amplify dissemination of gender equity-related articles and (2) collect proposed solutions to gender equity issues. Methods: In April 2018, eight published journal articles covering separate gender equity issues were presented in a 1-hour Twitter chat hosted by Physician's Weekly. Metrics data were collected before, during, and after the chat. During the chat, one question related to each article was tweeted at a time. Qualitative data were extracted from responses and evaluated for thematic content.

Results: In the 16-hour period during and following the chat, we tallied 1500 tweets from 294 participants and 8.6 million impressions (potential views). The Altmetric Attention Score of each article increased (average, 126.5 points; range, 91-208 points). Within the respective journal, the Altmetric Rank of seven articles improved (range, 3 to $\geq 19$ ), while the eighth maintained its \#1 rank. The one article for which share and download data were available experienced a $729 \%$ increase in shares following prechat posts and another $113 \%$ bump after the chat, a $1667 \%$ increase overall $(n=45-795)$. Similarly, downloads, and presumably reads, increased $712 \%$ following prechat posts and another $47 \%$ bump after the chat, a $1093 \%$ increase overall $(n=394-4700)$. We tallied 181 potential solutions to the eight gender equity-related questions.

Conclusion: Our results demonstrate that social media can be used strategically to increase the dissemination of research articles and collect solution-focused feedback.
\end{abstract}

Keywords: physicians, women, gender bias, translational research, social media, information dissemination

\section{Introduction}

$\mathbf{M}$ ANY DISPARITIES AFFECT women in medicine, including, but not limited to, compensation, ${ }^{1}$ promotion, ${ }^{2}$ leadership, ${ }^{2,3}$ and recognition awards. ${ }^{4}$ These macroinequities (large disparities) may be due, in part, to work environments that support microinequities (small disparities that are often unintentional, but which are increasingly being documented in research studies). For example, women are underrepresented among grand rounds speakers, ${ }^{5}$ and even when they

\footnotetext{
${ }^{1}$ Division of Infectious Diseases, University of Nebraska Medical Center, Omaha, Nebraska.

${ }^{2}$ Department of Surgery, Carver College of Medicine, University of Iowa Hospitals and Clinics, Iowa City, Iowa.

${ }^{3}$ Department of Radiology, Albany Medical College, Albany, New York.

${ }^{4}$ Department of Surgery, Lerner College of Medicine of Case Western Reserve University, Cleveland, Ohio.

${ }^{5}$ Breast Surgical Oncologist, Cleveland Clinic, Cleveland, Ohio.

${ }^{6}$ Breast Program, Cleveland Clinic Hillcrest Hospital, Cleveland, Ohio.

${ }^{7}$ Division of Gastroenterology and Hepatology, Department of Internal Medicine, Mayo Clinic College of Medicine, Rochester, Minnesota.

${ }^{8}$ Rutgers Robert Wood Johnson Medical School, South River, New Jersey.

${ }^{9}$ Department of Physical Medicine and Rehabilitation, MedStar National Rehabilitation Hospital, Washington, District of Columbia.

${ }^{10}$ Department of Physical Medicine and Rehabilitation, Harvard Medical School, Boston, Massachusetts.

${ }^{11}$ Department of Physical Medicine and Rehabilitation, Spaulding Rehabilitation Hospital, Boston, Massachusetts.

${ }^{12}$ Department of Physical Medicine and Rehabilitation, Massachusetts General Hospital, Boston, Massachusetts.

${ }^{13}$ Department of Physical Medicine and Rehabilitation, Brigham and Women's Hospital, Boston, Massachusetts.
} 
are invited, they are less likely than male counterparts to be introduced by professional titles such as "Doctor." 6 Women physicians are disproportionately underrepresented among authors of opinion articles in medical journals ${ }^{7}$ and left out of professional society newsletters. ${ }^{8}$ Women disproportionately experience gender bias in performance evaluations ${ }^{9,10}$ and letters of recommendation. ${ }^{11}$

In February 2018, a group of 22 women physicians from across the United States, including some of the authors of this report, gathered at a summit to discuss workforce gender equity. During discussions, it was obvious that, despite a large body of literature focused on disparities affecting women in medicine, progress has been troublingly slow, and that intervention would be required to accelerate closing of the gaps associated with previously documented disparities. ${ }^{12}$ Furthermore, it was recognized that most gender equity studies were being led by women who often had little or no funding and faced subsequent barriers to publication, including the assignment of submissions to journal editors who were not receptive to workforce gender equity articles and reviewers who were not subject matter experts.

Anecdotally, women physicians and researchers who are committed to this area of study often reported reductions in personal compensation due to decreased clinical time, reputational risk related to speaking out about gender bias, ${ }^{13}$ and increases in burnout symptoms. Given these and other equity issues, we realized that it may be necessary for women in medicine to actively search for ways to accelerate progress toward workforce gender equity. We hypothesized that women might be able to strategically disseminate research that documents disparities and recommends solutions through their vast social media networks. ${ }^{14}$

Five days after meeting, summit attendees participated in a proof-of-concept study of the impact of social media postings on research dissemination. During this preliminary study, attendees posted comments and information about a pregnancyrelated workforce gender equity article by Krause et al. titled "Impact of Pregnancy and Gender on Internal Medicine Resident Evaluations: A Retrospective Cohort Study"15 on Twitter and Facebook. AS Oxentenko, the senior author of that article and coauthor of this study, looked at the effects of gender and pregnancy on the evaluation scores given to internal medicine residents between July 1, 2004 and June 30, 2014. Scores given by faculty and peers to female residents who experienced pregnancy were compared with scores given to male residents whose partners experienced pregnancy. The authors found that, while there was no significant difference in evaluation scores given by faculty to these two groups, female residents were found to have lower peer evaluation scores in the postpartum period compared with their male counterparts (4.04 vs. 4.16, $p=0.0099$ ).

Proposed solutions included review of unconscious biases, parental leave policies, and resources available to new parents, as well as use of objective, milestone-based evaluations. This pregnancy study was initially published online in the Journal of General Internal Medicine in June of 2017. ${ }^{16}$ Eight months after publication, the journal website had counted 45 shares and 394 downloads (Fig. 1). In the week following posting of comments and information about the study by summit attendees, the number of shares increased to 310 (589\% increase), and the number of downloads, and presumably reads, increased to 2900 (636\% increase).

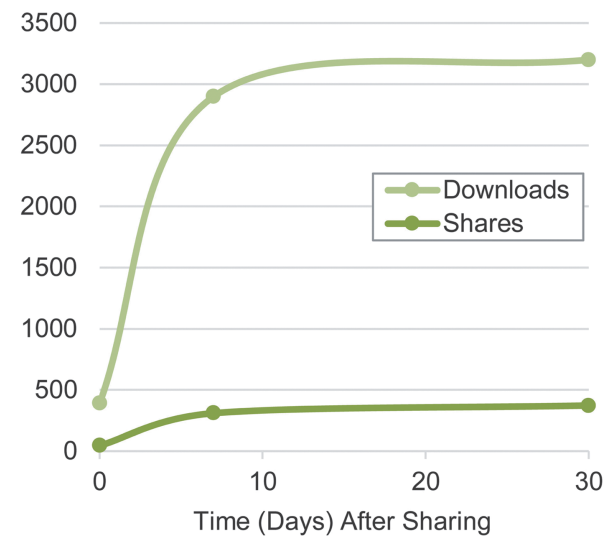

FIG. 1. Impact of proof-of-concept social media posts on dissemination of a pregnancy-related gender equity article. To gauge the potential impact of social media posts on dissemination of research, share and download counts for a pregnancyrelated workforce gender equity article 15 were obtained from the Journal of General Internal Medicine website16 on the day before, 7 days after, and 30 days after sharing of comments and information about the article by workforce gender equity summit attendees on Twitter and Facebook. Approximately 8 months after publication (Day 0), the article had accumulated 45 shares and 394 downloads. Within 1 week and 1 month after summit attendees posted this article on social media, the number of shares had increased 589\% $(n=310)$ and $729 \%(n=373)$, respectively. Similarly, 1 week and 1 month after summit attendees posted this article on social media, the number of downloads had increased $\sim 636 \%(n=2900)$ and $712 \%$ $(n=3200)$, respectively. Color images are available online.

After observing the marked increase in dissemination of the pregnancy-related workforce gender equity article following the proof-of-concept study, the senior author of this report (J.K.S.) decided to include it and seven other journal articles $(n=8)$ in a tweet chat (online conversation) that she was scheduled to lead on the topic of workforce gender equity. We then hypothesized that we could use social media in a strategic and coordinated manner before, during, and after this chat event to increase the metrics associated with each article. Metrics included, but were not limited to, alternative metric attention scores and ranks (i.e., algorithmically generated numbers that indicate how articles with doi numbers travel and compare virtually overall and within the publishing journal, respectively) and social media metrics (e.g., Twitter impressions, and tweets and retweets). We also aimed to glean insights about whether an increase in dissemination of the eight articles could help educate participating health care professionals about evidence-based disparities as well as accelerate formulation of strategic solutions by collecting qualitative information from participant comments.

\section{Methods}

To determine whether dissemination of gender equity research could be accelerated by a coordinated social media strategy, eight previously published journal articles (Table 1) were selected for inclusion in a 1-hour workforce gender equity-focused tweet chat on April 10, 2018, which was sponsored by Physician's Weekly $(P W)$ and guest-hosted by the senior author of this study (J.K.S.). For each, quantitative data 
Table 1. Profile of Articles Included in the April 10, 2018 PW Workforce Gender Equity Chat

\begin{tabular}{|c|c|c|c|c|c|c|}
\hline Article title & Journal & $\begin{array}{l}\text { Article } \\
\text { nickname }\end{array}$ & $\begin{array}{l}\text { First } \\
\text { author }\end{array}$ & $\begin{array}{l}\text { Online } \\
\text { publication } \\
\text { date, } \\
\mathrm{mm} / d \text { d/yyyy }\end{array}$ & $\begin{array}{c}\text { Print } \\
\text { publication } \\
\text { date, mm/yyyy }\end{array}$ & $\begin{array}{l}\text { Order of } \\
\text { inclusion in } \\
\text { PW Chat }\end{array}$ \\
\hline $\begin{array}{l}\text { Current status of gender and } \\
\text { racial/ethnic disparities among } \\
\text { academic emergency medicine } \\
\text { physicians }\end{array}$ & $\begin{array}{l}\text { Acad Emerg } \\
\quad \text { Med }\end{array}$ & Compensation & Madsen TE & 08/05/2017 & $10 / 2017$ & 1 \\
\hline $\begin{array}{l}\text { Gender differences in academic } \\
\text { medicine: retention, rank, and } \\
\text { leadership comparisons from } \\
\text { the national faculty survey }\end{array}$ & Acad Med & Promotion & Carr PL & $01 / 30 / 2018$ & $\begin{array}{c}\text { Not; as of } \\
08 / 10 / 2018\end{array}$ & 2 \\
\hline $\begin{array}{l}\text { Impact of pregnancy and gender } \\
\text { on internal medicine resident } \\
\text { evaluations: a retrospective } \\
\text { cohort study }\end{array}$ & $\begin{array}{l}J \text { Gen Intern } \\
\quad \text { Med }\end{array}$ & Pregnancy & Krause ML & $02 / 13 / 2017$ & 06/2017 & 3 \\
\hline $\begin{array}{l}\text { Women physicians are } \\
\text { underrepresented in } \\
\text { recognition awards from the } \\
\text { Association of Academic } \\
\text { Physiatrists }\end{array}$ & $\begin{array}{l}\text { Am J Phys } \\
\text { Med Rehabil }\end{array}$ & Awards & Silver JK & 06/09/2017 & $01 / 2018$ & 4 \\
\hline $\begin{array}{l}\text { Gender differences in attending } \\
\text { physicians' feedback to } \\
\text { residents: a qualitative } \\
\text { analysis }\end{array}$ & $\begin{array}{l}\text { J Grad Med } \\
\text { Educ }\end{array}$ & Evaluation & Mueller AS & $10 / 28 / 2017$ & $10 / 2017$ & 5 \\
\hline $\begin{array}{l}\text { It is time for zero tolerance for } \\
\text { sexual harassment in academic } \\
\text { medicine }\end{array}$ & Acad Med & Me Too & Bates CK & $11 / 09 / 17$ & $02 / 2018$ & 6 \\
\hline $\begin{array}{l}\text { The relationship between } \\
\text { perceived gender judgment } \\
\text { and well-being among surgical } \\
\text { residents }\end{array}$ & Am J Surg & Judged & Salles A & $11 / 06 / 2017$ & 02/2018 & 7 \\
\hline $\begin{array}{l}\text { Where are the women? The } \\
\text { underrepresentation of women } \\
\text { physicians among recognition } \\
\text { award recipients from medical } \\
\text { specialty societies }\end{array}$ & $P M R$ & Metrics & Silver JK & 06/09/2017 & $08 / 2017$ & 8 \\
\hline
\end{tabular}

were collected from several sources, including Altmetric, ${ }^{17-19}$ Twitter, ${ }^{20,21}$ and TweetReach from Union Metrics ${ }^{22}$ (Table 2). The first two sources (Altmetric and Twitter) make their data publicly available, while the third (TweetReach) is a commercially available resource to which $P W$ subscribes.
During the chat, $P W$ tweeted one question per article and invited the participants to respond. Questions were designed by the guest host and senior author of this study (J.K.S.) in advance of the event. Data were manually abstracted and validated at various times by investigators before, during, and

Table 2. Sources, Names, and Definitions of Metric Terms

\begin{tabular}{|c|c|}
\hline $\begin{array}{l}\text { Metric source and } \\
\text { name }\end{array}$ & Metric definition \\
\hline \multicolumn{2}{|l|}{ Altmetric ${ }^{18,19}$} \\
\hline Attention score & $\begin{array}{l}\text { "Automatically calculated, weighted count of all of the attention a research output has received" } \\
\text { across postpublication peer review, social media, mainstream media, and other sources }\end{array}$ \\
\hline Rank & $\begin{array}{l}\text { Rank by attention score when compared with similar articles by publication time, title, or journal of } \\
\text { publication }\end{array}$ \\
\hline Summary counts & $\begin{array}{l}\text { Counts of how many authors from each source type (Twitter, Mendeley, Blogs, etc.) have } \\
\text { mentioned or shared the article }\end{array}$ \\
\hline \multicolumn{2}{|l|}{ Twitter 20,21} \\
\hline Impressions & Potential views, number of tweets multiplied by number of followers \\
\hline Engagements & Number of times a user interacted with the tweet \\
\hline Link Clicks & Number of clicks on a URL or card in the tweet \\
\hline Likes & Number of clicks on the heart icon associated with the tweet, indicative of appreciation for the tweet \\
\hline Retweets & Number of times an existing tweet was shared publicly by followers \\
\hline
\end{tabular}


after the chat as noted. Publicly available Twitter analytics for each question were captured by $P W$ and sent to the research team for analysis. Additional quantitative analysis included TweetReach data associated with \#PWChat during and for 15 hours after the chat concluded. One of the journals (Journal of General Internal Medicine) provided information on its website regarding article downloads and shares as well. Qualitative information was collected from participant responses. Because this is not direct human studies research and the data reported are available in the public domain, Partners Human Research Committee/IRB determined that no institutional review board approval was required. See Supplementary Table S1 for STROBE checklist details.

\section{Results}

Each of the eight articles used in the $P W$ workforce gender equity chat focused on a different topic (Table 1), including the core macroinequities of financial compensation (Compensation), ${ }^{23}$ academic rank and leadership role promotion (Promotion), ${ }^{2}$ and recognition awards (Awards). ${ }^{24}$ Microinequity articles included in the chat focused on internal medicine attending and peer evaluations of residents who became new parents while in training (Pregnancy) ${ }^{15}$ and gender differences in attending physician feedback to residents (Evaluation). ${ }^{25}$ Three additional articles were included that focused on sexual harassment (Me Too), ${ }^{26}$ metrics that can be used by medical societies to analyze gender equity (Metrics), ${ }^{4}$ and well-being among trainees who feel judged on the basis of gender identity (Judged). ${ }^{27}$

\section{Altmetric analytics}

Using publicly available data provided by the company Altmetric, we tracked various metrics for each article before and after the $P W$ chat (Table 2). Not surprisingly, because links to all articles were shared on Twitter during both the announcement phase and the event itself, all Altmetric Attention Scores increased (Fig. 2 and Table 3); average, 126.5 points; range, 91-208 points; $p$-value, $<0.0001$; 95\% CI, 96.5-156.5), with the largest increase associated with the Promotion article and the smallest increase associated with the Me Too article.

In contrast to Altmetric Attention Score, which increases as an article receives more attention, Altmetric Rank generally decreases as an article receives more attention (e.g., moves from a rank of 10 to a rank of 1). Of the eight articles, seven experienced an improvement in Altmetric Rank within the respective journal (Fig. 3 and Table 3; average, 8.6; range, 0 to $\geq 19 ; p$ value, 0.005 ; and $95 \% \mathrm{CI}, 3.5-13.7)$. The article with the largest improvement in rank within the respective journal was the Me Too article, which, unranked at the time of the chat's announcement (Day 0), saw greater than a 19point improvement. Notably, the magnitude of this improvement is conservative and represents improvement between this article's first recorded rank of 35 in the journal Academic Medicine on Day 7 and its Day 49 rank of 16. The Metrics article showed no improvement in rank within the journal $P M \& R$ because it retained its rank of \#1 (out of nearly 1000 articles) throughout the study period.

\section{Twitter analytics}

To drive dynamic conversation, participants were asked one question related to each article during the chat. Questions were tweeted a few minutes apart so that participants had time to read and respond to each question. The tweet itself focused on the journal article and included the article's URL.

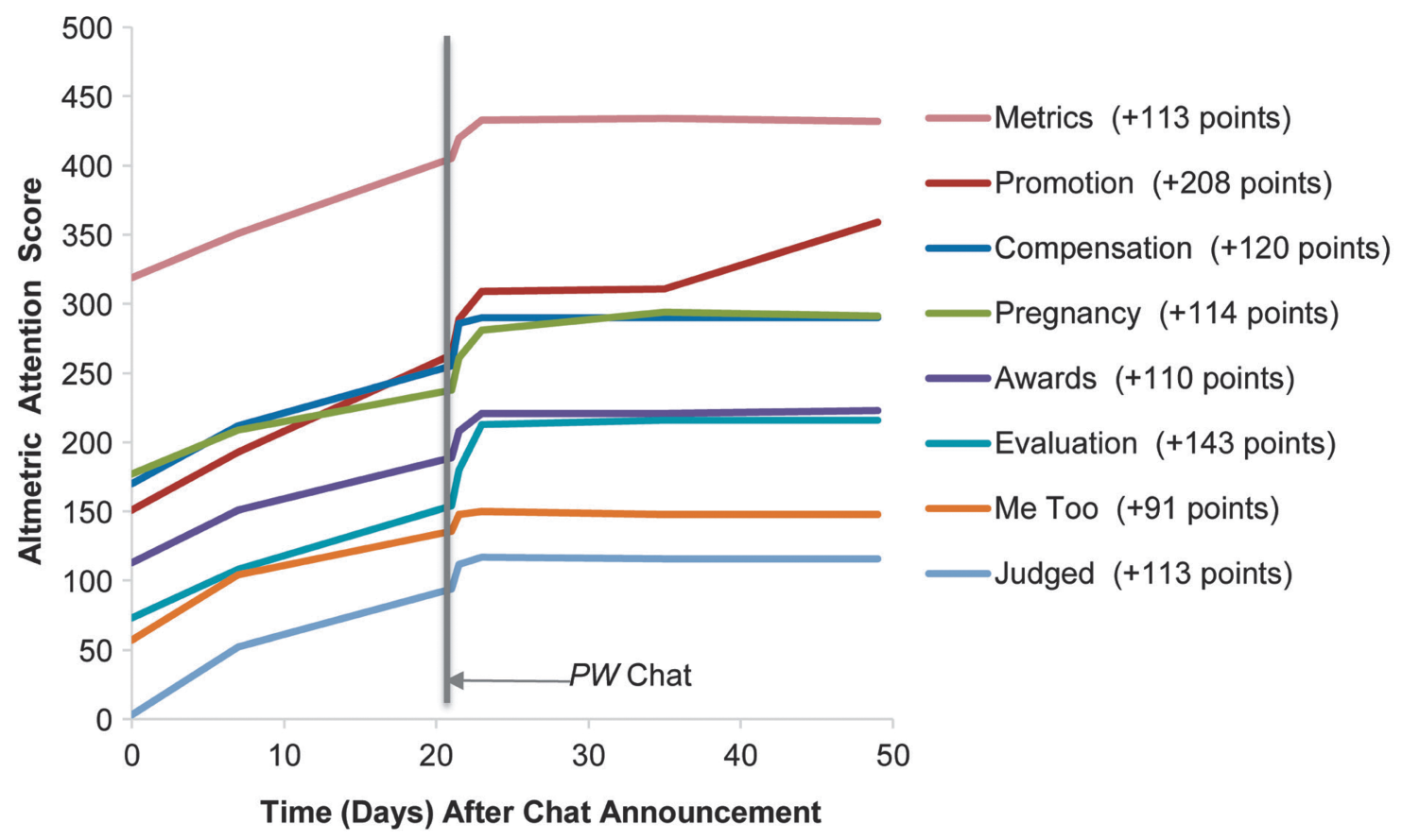

FIG. 2. Impact of a coordinated chat strategy on article Altmetric Attention Score. Altmetric Attention Scores are shown for the eight selected articles at the time of announcement of the upcoming chat (Day 0), before the chat (Days 1-20) and following the chat (Days 21-49). Improvement in Altmetric Attention Score between chat announcement (Day 0) and 1 month after the chat (Day 49) is shown in parentheses behind each article nickname. Color images are available online. 


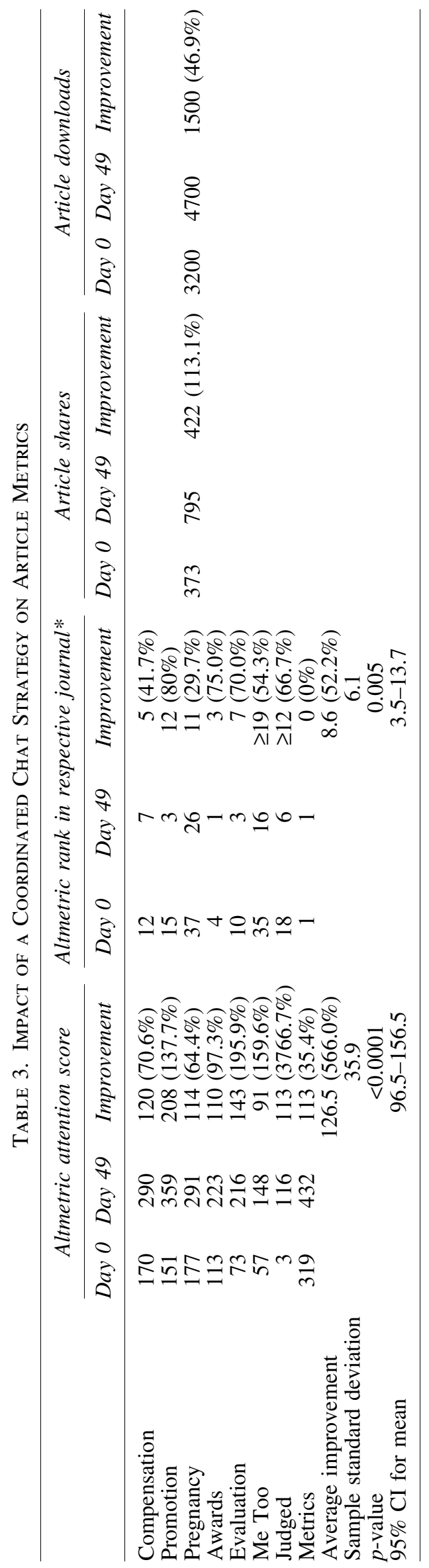

The question was placed on an attached image (slide style) that could be seen by participants at the same time as the message in the tweet(chat can be found through Twitter Advanced Search using the date of April 10, 2018 combined with \#womeninmedicine and posts by @physicianswkly). For example, the first tweet stated, "Madsen et al. studied \#emergencymedicine physicians and found women earned less than men regardless of rank, clinical hours, or training. Other specialties have similar findings. Report link [URL] \#PWChat \#WomenInMedicine \#PROWD \#HeForShe \#EqualPayDay2018." The attached image contained the following: "Q1 What do you think can be done to close the gender wage gap?"

It is important to note that each tweet carries its own "tweet activity dashboard",21 that (1) tracks the cumulative level of user interest and (2) can be viewed by the originator of the tweet. Of the different types of data included on the tweet activity dashboard, we focused on impressions, engagements, and link clicks (Table 2). As listed, each measure requires more user involvement and serves as an indicator of the depth of the Twitter user's interest. Data were recorded 2 days after the chat as a measure of immediate chat activity and 2 weeks after the chat as a measure of sustained interest.

Two days after the chat, the articles that were associated with the most impressions (Fig. 4A) were Promotion $(n=7880)$ and Compensation $(n=7480)$. Two weeks after the chat, impressions for all articles had improved, with three articles reaching 9000 impressions - Compensation, Pregnancy, and Promotion. The article that had the fewest impressions at the 2-day $(n=2837)$ and 2-week $(n=3138)$ mark was the Me Too article that focused on sexual harassment. Regarding interactions with each question tweet (Fig. 4B), at the 2-day mark, the Promotion article had the most engagements $(n=252)$, while the Me Too article had the fewest engagements $(n=62)$. At the 2 -week mark, all articles had received additional levels of engagement, the Pregnancy article receiving more than the others. Link clicks, which require the most effort in that the user must click on the URL to the journal article, had the lowest counts overall (Fig. 4C; 2-day mark range, 10-36 link clicks; 2-week mark range, 12-37 link clicks). Nevertheless, all articles had gained additional link click counts at the 2-week mark. At both the 2-day and 2-week marks, the articles with the most link clicks were Evaluation and Promotion.

\section{TweetReach analytics}

To further analyze who participated in the chat and their impact, we analyzed $P W$ 's TweetReach report for \#PWChat during the study period. TweetReach, a commercial service to which $P W$ subscribes, tracks a series of social media analytics, including, but not limited to, the activity of Twitter contributors. Because (1) we anticipated some level of Twitter activity both before (e.g., promotion) and after (e.g., extended conversation) the chat, (2) the chat was scheduled to last just 1 hour, and (3) we wanted to focus analysis on active discussion between participants, we examined activity over a 16-hour period that started with the beginning of the chat and ended on the following day (15 hours after the end of the chat).

During the analysis period, TweetReach counted 1500 tweets from 294 contributors that resulted in more than 8.6 


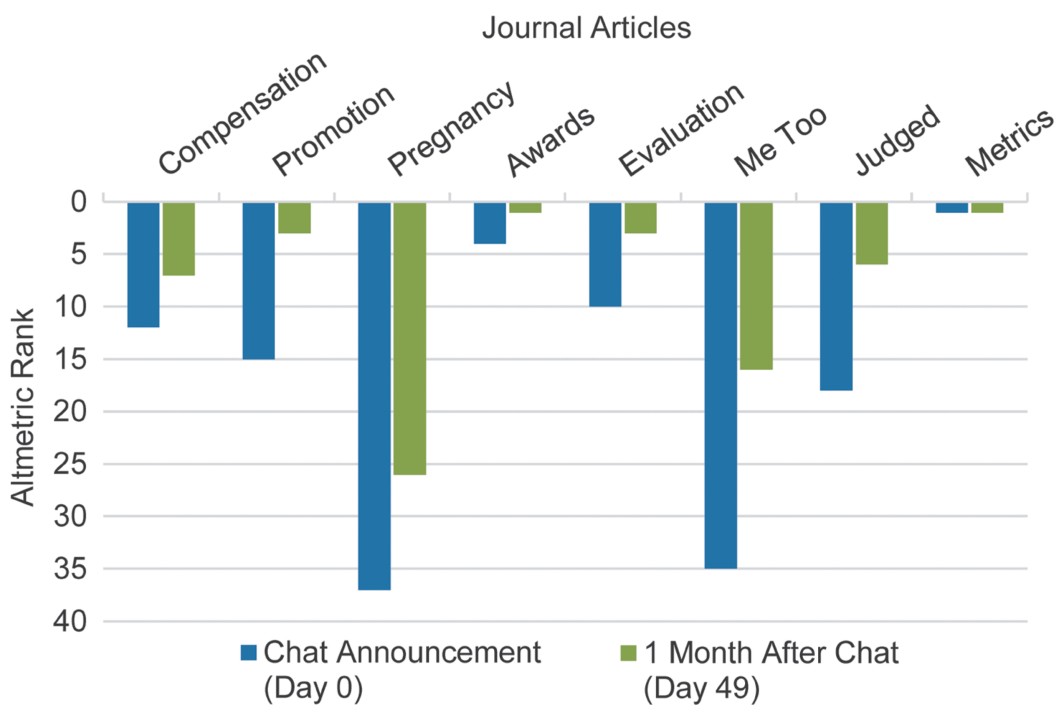

FIG. 3. Impact of a coordinated chat strategy on article Altmetric Rank. Because Altmetric Rank decreases as an article receives more attention (e.g., moves from a \#10 to a \#1 rank) and to visually represent improvement in rank, the vertical axis in this chart was reversed. The Altmetric rank improved for seven of the eight articles between announcement of the chat (Day 0) and 1 month after the chat (Day 49). The improvement seen in the ranks of the MeToo and Judged articles is conservative as these articles were unranked on the day the chat was announced. For these articles, the Altmetric Ranks on Day 7 were substituted for the ranks on Day 0. Although the Metrics article showed the least improvement in rank during the study period, it could not have improved, holding and retaining the \#1 rank from chat announcement through the end of the study period. Color images are available online.

million impressions, potentially reaching 569785 Twitter user accounts. The top 10 contributors ranked by number of tweets and retweets (Fig. 5A) included 8 individual women physicians, 1 woman veterinarian, and the sponsoring organization, $P W$. These users accounted for $1183(78.9 \%)$ of the 1500 tweets posted during the analysis period. The top 10 contributors by impressions (Fig. 5B) included 7 individual women physicians and 3 nonprofit professional medical organizations. Combined, these users accounted for 7.0 million $(81.6 \%)$ of the 8.6 million total impressions. Not surprisingly, $P W$ (the sponsoring organization) was the top contributor when measured by both mentions (mentioning of another user's name; $n=617)$ and retweets $(n=126)$.

Among the 1500 tweets counted by TweetReach, 1081 were original tweets (messages sent out), 220 were replies (replies to messages), and 199 were retweets (reposting or sharing of messages by another Twitter user). The most frequently shared tweet was retweeted 34 times and read "A2 Findings are disturbing. Women less likely to attain senior leadership positions than men AFTER adjusting for academic productivity, OR 0.49 . Highlights problem with the system, NOT the women. \#PWChat \#WomenInMedicine \#PROWD \#HeForShe \#ILookLikeASurgeon [URL]." That tweet addressed the Promotions article, which had the most impressions, engagements, and link clicks of all the articles at the 2-day postchat mark. Interest in this article continued, as it was ranked second for engagements and link clicks and third for impressions at the 2-week postchat mark.

\section{Article shares and downloads}

As a measure of interest and participant follow-through, we examined article download and share data. These types of data were available only for the Pregnancy article through the Journal of General Internal Medicine website. ${ }^{16}$ As described in the introduction of this report, prechat proof-ofconcept social media posts by summit attendees were associated with increases in both shares and downloads of the article (Fig. 1). Approximately 1 month after the gender equity summit and just before the chat's announcement, shares had increased by $729 \%(n=45-373)$ and downloads had increased by $712 \%(n=394-3200)$.

$P W$ announced and began publicizing the chat $\sim 3$ weeks before the scheduled date. Immediately before the chat started, this article had accumulated 580 shares, which increased to 729, 770, 793, and 795 shares immediately, 2 days, 2 weeks, and 1 month after the chat, respectively, suggesting that the chat and associated promotion may have contributed to an additional $113 \%$ increase in shares (Table $3 ; n=373$ 795). Downloads, which numbered $\sim 3900$ immediately before the chat, increased to 4500 after 2 weeks and to 4700 after 1 month of the chat. These results suggest that the chat and associated promotion may have contributed to an additional $47 \%$ increase in downloads (Table $3 ; n=3200-$ 4700). The total impact of social media interventions (prechat proof-of-concept study plus coordinated $P W$ chat strategy) on dissemination of this article, which had already been available for 8 months, was a $1667 \%$ increase in shares $(n=45-795)$ and a $1093 \%$ increase in downloads $(n=394-4700)$.

\section{Manual abstraction of solution-related data}

Manually abstracted Twitter data included reactions to the eight article questions posed during the chat (Table 4). The questions garnered 195 likes, 97 retweets, and 181 direct 

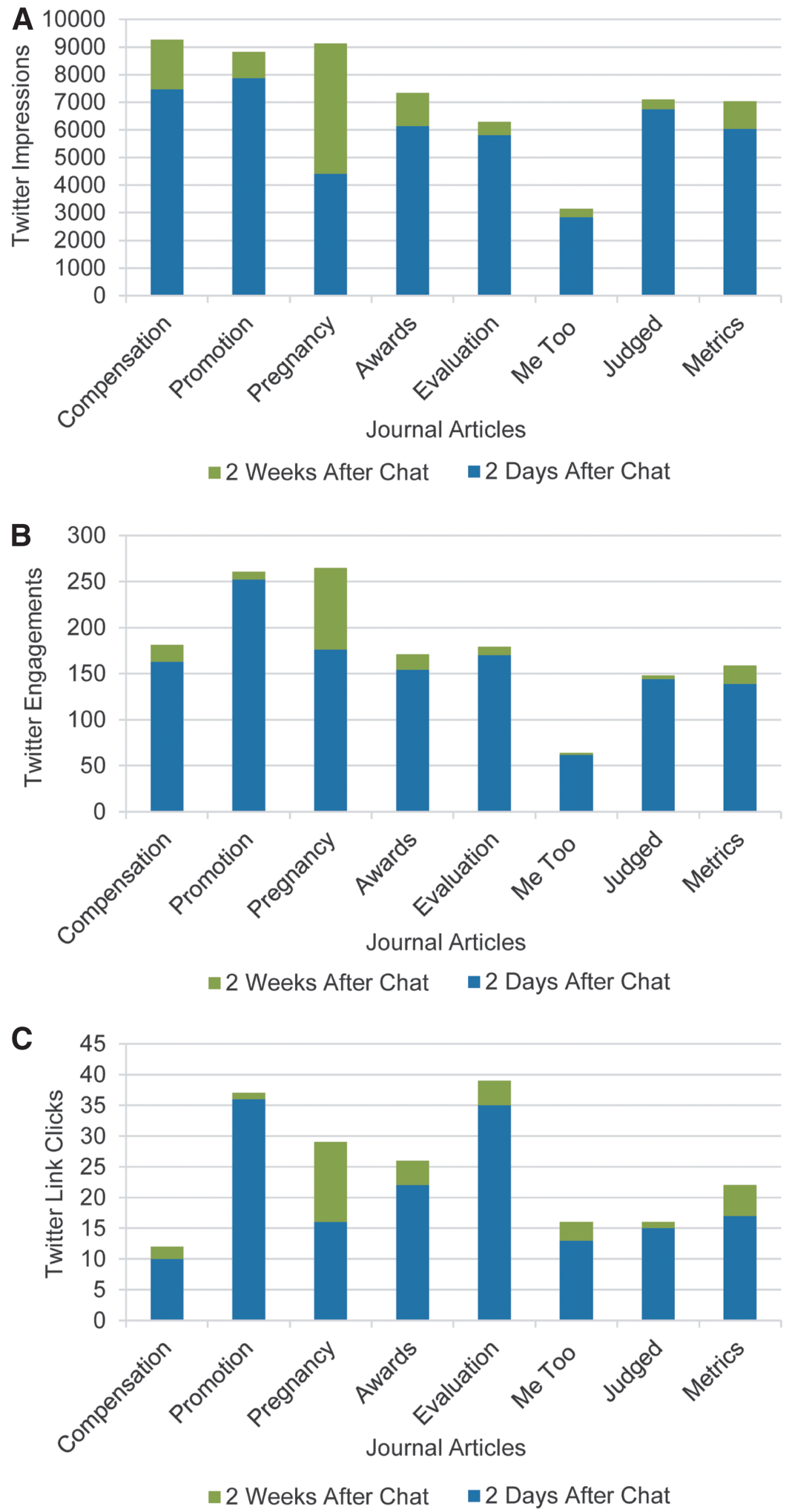

FIG. 4. (A-C) Counts of Twitter impressions, engagements, and link clicks for each question tweet. Counts of impressions (A; potential views), engagements (B; user interactions), and link clicks (C; clicks on the link to the article's URL) were recorded for each article's question tweet. Cumulative data were recorded 2 days after the chat as a measure of immediate activity/interest and again 2 weeks after the chat as a measure of sustained interest. Color images are available online. answers. As hoped for in a dynamic solutions-focused chat, the 181 answers garnered more reactions than the questions, 1731 likes and 656 retweets. The third question, associated with the Pregnancy article and regarding optimization of medical training during pregnancy and prevention of lower peer evaluation scores for women, was associated with the largest number of answers $(n=34)$, likes $(n=419)$, and retweets $(n=153)$. The eighth question, which was the last question of the chat and related to how to engage professional societies in examining their inclusion data and gender gaps in a timely manner, was associated with the lowest number of answers $(n=11)$. 


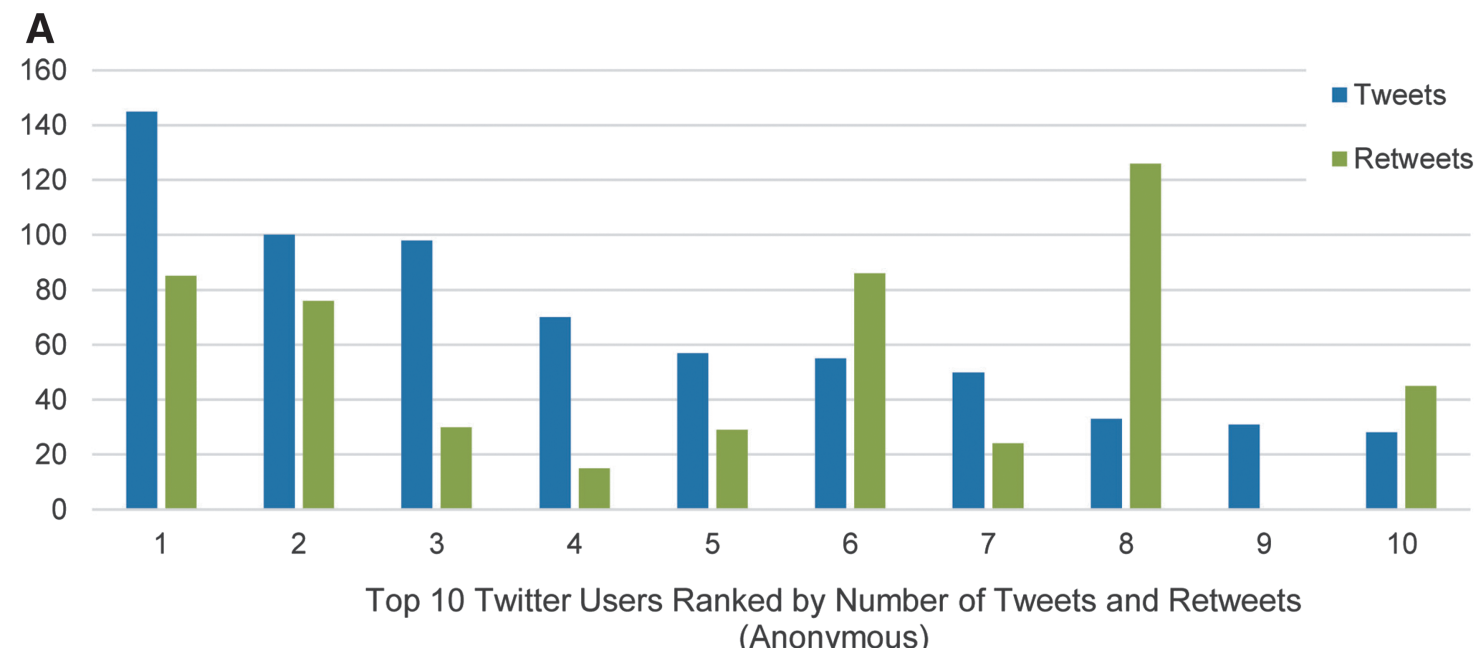

B

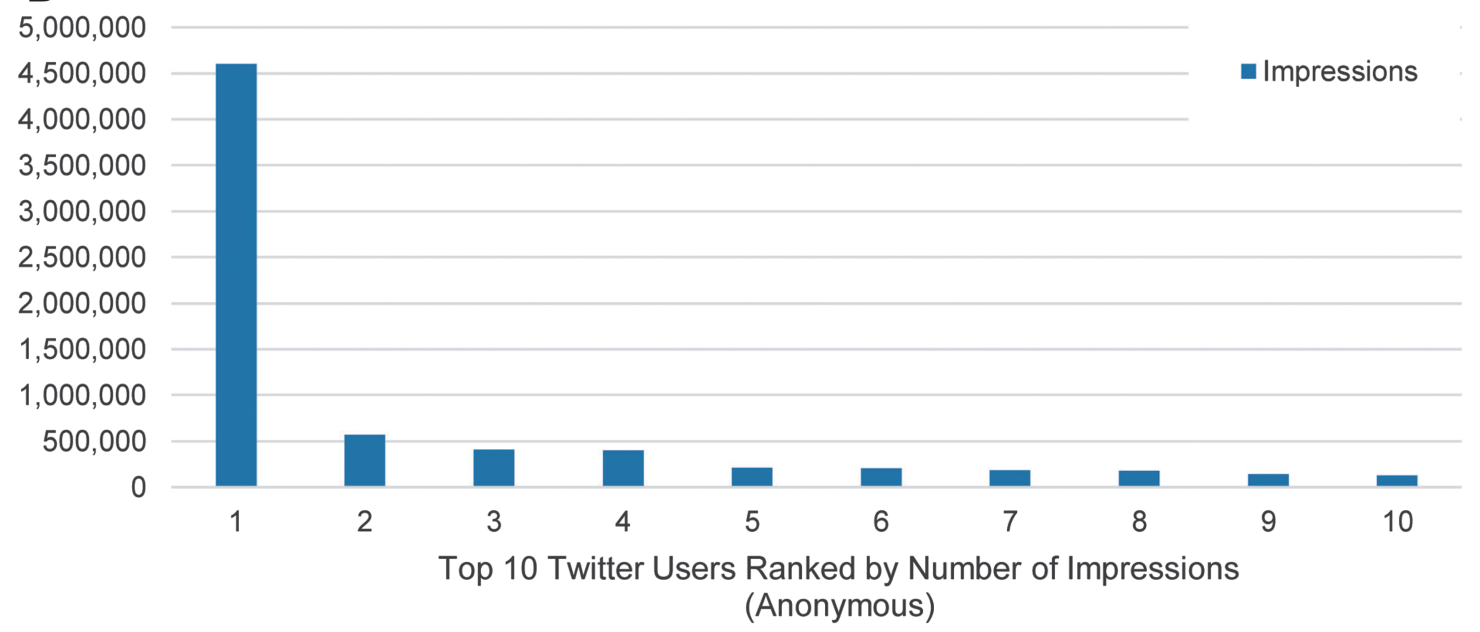

FIG. 5. (A, B) Top 10 participants in the chat by tweets and impressions. The charts show the activity associated with the top 10 Twitter users ranked by (A) the sum of tweets and retweets and (B) impressions during a 16-hour period that started with the beginning of the PW chat. The top 10 Twitter users when ranked by sum of tweets and retweets (indicative of who was most actively participating in the chat) included 8 individual women physicians, 1 woman veterinarian, and the sponsoring organization, PW. The top 10 Twitter users contributed to the majority of tweets and retweets, combining to account for over $1100(78.9 \%)$ of the 1500 total posted during a 16-hour period that started at the beginning of the chat. The top 10 Twitter users when ranked by number of impressions (indicative of whose tweets were reaching the largest number of followers) included seven individual women physicians and three nonprofit professional medical organizations. Combined, the top 10 Twitter contributors accounted for $\sim 7$ million $(81.6 \%)$ of the 8.6 million impressions, with the highest influencer solely conferring over 4.5 million impressions due to having a very large number of Twitter followers. Color images are available online.

Table 4. Chat Question-Related Tweet Activity

\begin{tabular}{lccccr}
\hline $\begin{array}{l}\text { Question \# } \\
\text { and article }\end{array}$ & $\begin{array}{c}\text { Question likes, } \\
\text { No. }\end{array}$ & $\begin{array}{c}\text { Question retweets, } \\
\text { No. }\end{array}$ & $\begin{array}{c}\text { Direct answers, } \\
\text { No. }\end{array}$ & $\begin{array}{c}\text { Answer likes, } \\
\text { No. }\end{array}$ & $\begin{array}{c}\text { Answer retweets, } \\
\text { No. }\end{array}$ \\
\hline 1 Compensation & 24 & 12 & 24 & 252 & 96 \\
2 Promotion & 32 & 17 & 25 & 313 & 131 \\
3 Pregnancy & 23 & 7 & 34 & 419 & 153 \\
4 Awards & 26 & 20 & 28 & 263 & 168 \\
5 Evaluation & 25 & 11 & 22 & 74 & 49 \\
6 Me Too & 10 & 6 & 17 & 74 & 75 \\
7 Judged & 22 & 8 & 11 & 1731 & 31 \\
8 Metrics & 33 & 16 & 181 & 656 \\
Total & 195 & 97 & & & \\
\hline
\end{tabular}

This table shows counts of reactions to article questions posed during the chat: question likes, question retweets (shares), direct answers to the questions, and likes and retweets of those answers. 
Because the secondary goal of the study focused on gathering solutions or ways to promote workforce gender equity, we used numbers of likes to identify the most popular solutions proposed by chat participants (Table 5). Important concepts gleaned from the solutions proposed by chat participants (Table 6) included needs for the following: (1) assessment of personal gender-related implicit bias among faculty and trainees that is followed by appropriate interventional training; (2) qualitative and quantitative research regarding the presence, type, and impact of inequities and biases from local to national levels; (3) transparent reporting of research results; (4) commitment and accountability among leadership to decrease bias and disparities; (5) improved mentorship and sponsorship; (6) assessment of current systems and processes designed to decrease the influence of subjectivity and opportunity for bias; and (7) cultural (institutional) interventions focused on increased flexibility in schedules, work, and candidacy for promotion.

\section{Discussion}

Our results demonstrate that use of a coordinated social media chat strategy increased the dissemination of information about, and presumably interest in, the eight journal articles selected for this report. Specifically, within a 16-hour period that began at the start of the 1-hour online chat, we counted 1500 tweets, replies, and retweets from 294 contributors, which resulted in 8.6 million impressions, potentially reaching 569785 Twitter users.

Our social media chat strategy resulted in the following: (1) an increase in the Altmetric Attention Score of all eight of the selected articles, and (2) improvement in the Altmetric Rank of seven of the eight, when compared with other articles in their respective journals. Notably, while the Altmetric Rank of one article did not improve within the respective journal, it was already ranked \#1 and maintained that rank during the study period. Moreover, for the one article (Pregnancy) for which we had access to share and download data, implementation of both the prechat proof-of-concept social media sharing by workforce gender equity summit attendees and the coordinated social media chat strategy resulted in a marked (1093\%) increase in the number of article downloads, and presumably reads, more than 8 months after publication.

By asking for answers (solutions) to targeted questions about eight separate areas of inequity affecting women in medicine, we were able to develop a list of initiatives that included specific actions. Interestingly, a solution proposed for one issue often proved to be a solution proposed for one or more other areas of inequity, demonstrating that multiple issues might be addressed through similar measures. As an example, addressing bias was recommended as a solution for each of the eight inequity questions, with specific aspects, including assessment, data reporting, education, and providing feedback to faculty, trainees, and those in leadership. Importantly, this "packaged content" (questions about inequity followed by real-time proposal of solutions) was viewed by a self-selected audience of engaged individuals and organizations who were interested in driving positive change.

Research dissemination and the implementation of solutions are both notoriously slow, ${ }^{28}$ and social media may provide new avenues to accelerate this process. ${ }^{14,29}$ Indeed, the value of disseminating research through vast social media networks comprising physicians, scientists, policy makers, and others is increasingly being recognized. A recent report by Shillcutt and Silver in the New England Journal of Medicine focused on how women in medicine, in particular, are using virtual platforms to connect. ${ }^{14}$ Use of Twitter has been linked to increased citations of publications and impact factors for journals. ${ }^{30}$ Niehaus et al. also described how journals may work strategically with physicians and researchers in a loosely coordinated manner to enhance the dissemination of research through Twitter. ${ }^{29}$

Bibliometrics, or the "statistical analysis of...publications,",31 are often categorized as conventional or alternative. Conventional metrics such as journal impact factor, H-index, and citation counts have been widely adopted. However, all are also associated with well-documented limitations, including that it takes a long time to measure impact. ${ }^{28}$ For example, citation counts take years to accumulate and are influenced by a host of factors such as the researcher's visibility in the scientific community. Moreover, conventional metrics may favor men for many reasons. For example, women are underrepresented among grand rounds speakers ${ }^{5}$ and authors of perspectives in journals, ${ }^{7}$ and women self-cite less often than men. ${ }^{32}$ In contrast, alternative metrics (e.g., Altmetric Attention Score and Rank, tweets and retweets, and journal website share and download counts) provide faster measures of a journal article's dissemination. These "realtime" metrics are increasingly being used in conjunction with conventional metrics for measuring academic productivity and influence. ${ }^{33-38}$ Like conventional metrics, alternative metrics may be manipulated, and companies that have developed alternative metrics algorithms do employ "antigaming" strategies that are still evolving.

Alternative metrics complement conventional metrics in measuring engagement with research, including dissemination. Previous reports have shown that most physicians, ${ }^{39-41}$ like the majority (69\%) of adults in the United States, use social media, with $24 \%$ of adults using Twitter as of January $2018 .^{42}$ Twitter has been reported to be the most common form of social media used for health care communication, ${ }^{43}$ which suggests that there is the potential to reach a large audience very quickly through our strategy.

Although Twitter has been previously used to disseminate $\operatorname{articles}^{29,44,45}$ and analyze themes in responses, ${ }^{46-48}$ strengths of this study include the use of an innovative and robust a priori method of strategically choosing a series of articles for dissemination through a tweet chat combined with multiple avenues of data collection to assess the feasibility of this approach, impact on dissemination, and capability to not just search for themes of concern, but actual solutions to problems. The $P W$ tweet chat is a regular event that has an established audience and a successful structure for hosting of chats. In addition, the topic of this chat was widely promoted before the event to encourage participation. Moreover, selection of articles highlighting different gender inequities was deliberate, increasing the likelihood that the chat would be relevant to a larger audience.

Furthermore, the potential to reach millions of widespread, self-selected, engaged parties on Twitter is likely higher than could have been achieved traditionally by independent journals, authors, or journal clubs ${ }^{49}$ and resulted in more rapid dissemination of article information. By opting to focus the chat on solutions and not discussion of the articles in detail 
Table 5. Most Popular Workforce Gender Equity Solutions Proposed by Chat Participants

\begin{tabular}{ll}
\hline Question \# and article & \multicolumn{1}{c}{ Question } \\
\hline 1 Compensation & $\begin{array}{c}\text { What do you think can be done to close } \\
\text { the wage gap? }\end{array}$ \\
& \\
& \\
& The authors recommended that \\
& institutions examine the climate for \\
& women to ensure their academic \\
& capital is fully utilized and equal \\
& opportunity exists for leadership. \\
& What do you think deans/chairs and \\
& other leaders should be doing if \\
& women's qualifications are similar, \\
& but they still are not advancing \\
equitably? & What do you think medical education \\
leaders should do to optimize \\
training throughout pregnancy and \\
prevent low peer evaluation scores \\
for women? \\
What do you think medical society \\
leaders should do to ensure that \\
women members are equitably \\
recognized for their important \\
contributions?
\end{tabular}

Pregnancy and parenthood must be recognized as an expected part of life rather than an inconvenience to peers and employers. Parental leave support can assist this culture change.

Women should celebrate other women through award nominations.

initiatives to address the gap.

Understanding the salaries of others provides a foundation to negotiate and/or advocate for yourself or others.

The sponsorship of women by both women and men is essential. It should no longer be considered an 'honor' to serve as the only woman in a specific leadership role.

Societies should ensure equity in their leadership in support of diversity of awardees. If diverse candidates are not available, the society should request nomination of women and other underrepresented groups.

5 Evaluation What do you think medical education leaders should do to ensure that women are given consistent and constructive feedback during training?

$6 \mathrm{Me}$ Too

Q6: What do you think leaders at medical societies should be doing to ensure that women are safe from sexual harassment at conferences?

\section{Judged}

8 Metrics
There is a body of literature-in medicine and beyond-supporting that women are often judged worse than men when their gender is known, but not when their gender is disguised. So what should medical education leaders do to decrease gender-based judgment?

How can we get our professional societies to examine inclusion data for women members and address gaps expeditiously?
Providing feedback to minimize the influence of gender bias requires consideration of two questions: (1) How would the feedback sound if given to the opposite gender? If the answer is not appropriate, then do not give it. (2) Is the feedback strictly related to work performance? If not, adjust the feedback.

When you encounter articles or arguments regarding how women physicians are a cause of the physician shortage based on work load or leaving medicine, or those that suggest women should choose a different subspecialty, take an active role in combating these inaccuracies through verbal communication and/or writing. Consider engaging a more senior woman in the process.

Provide all educators and trainees training on implicit bias and stereotype threat to increase understanding and recognition.

Provide a specific path forward with a published process to achieve gender in medical societies as reflected in the journal article mentioned in question 8.

The most popular solution proposed by chat participants for each article question was that which accumulated the most number of likes. Does not include posts that did not offer a solution. Edited for length. 
Q1: What do you think can be done to close the wage gap?

- Assessment and transparent reporting of salary and benefits

- Teach negotiation skills

- Standardize contracts, salaries, and bonuses

- Mentorship to increase promotion

- Assessment of bias in recruitment and promotion processes

- Involve Human Resources to ensure equitable offers based on position/seniority

- Flexibility in schedules

- Subsidized child care

- Parental leave for men and women

- Data-driven engagement of leadership for change

Q2: The authors [of the Promotion article] recommended that institutions examine the climate for women to ensure their academic capital is fully utilized and equal opportunity exists for leadership. What do you think deans/chairs and other leaders should be doing if women's qualifications are similar, but they still are not advancing equitably?

- Revise promotion and tenure processes to mitigate bias and equitably weight criteria

- Improve mentorship and sponsorship, with training

- Root cause analysis of inequities

- Implicit bias training

- Assess workplace culture

- Promote support and salary equity

- Institutional committee(s) should report on processes and equity

- Require data on advancement selection decision-making and assess for bias within committees

- Annual evaluations with leadership to determine barriers to advancement

- Blind gender in review processes

- Redefine "early career"

- Leadership and career training for women

Q3: What do you think medical education leaders should do to optimize training throughout pregnancy, and prevent low peer evaluation scores for women?

- Address stigma through support for pregnancy and family development

- Support parental leave

- Increase flexibility of schedules during pregnancy and after leave for trainees and faculty

- Utilize alternative providers for maternity leave to decrease burden on colleagues

- Disseminate the Pregnancy Discrimination Act

- Use objective questions to assess milestone achievements

- Build schedules with redundancy for leave without "payback" contingency

- Provide adequate lactation rooms and child support for employees, trainees, and students

- Develop policies for parental leave and schedule flexibility for trainees and faculty

- Assess and educate regarding implicit bias against pregnancy and families

- Allow professional development to encompass pauses without penalty

- Enforce equitable durations of parental leave for both mothers and fathers

- Discuss physician inequities in formal journal clubs

- Avoid penalties for nonparticipation in nonoffice hour activities

Q4: What do you think medical society leaders should do to ensure that women members are equitably recognized for their important contributions?

- Research why women are not recognized

- Educate leaders about disparities

- Seek diverse applicants and monitor diversity among awardees

- Create Women In Medicine Awards to highlight accomplishments

- Intentionally nominate women for awards

- Ensure nominating/leadership committees comprise a diverse group

- Unconscious bias training for leadership and nominating committees

- Formal assessment of award nomination evaluations to minimize subjectivity and bias influence

- Transparent reporting of data regarding gender equity

- Accountability for equity among award recipients and leadership

- Establish an overall award for achievement in gender parity

- Amplify the success of others to increase recognition

- Gender equity in editorial/expert panels

Q5: What do you think medical education leaders should do to ensure that women are given consistent and constructive feedback during training?

- Implicit bias training for evaluators

- Answer objective work-related performance questions such as "What 3 things did this trainee do well?" and "What 3 things can this trainee continue to work on?"

- Provide real-time, continuous feedback, not retrospective feedback

- Use Faculty Z-scores to correct for their typical bias

- Feedback should focus on actionable items with measurable outcomes, not personality traits or other unmeasurable criteria

- Request feedback on audits before release to trainees, asking for constructive details 
TABle 6. (CONTINUED)

- Standardize remediation and improvement strategies for struggling physicians/trainees

- Avoid gender-based stereotypes and expectations of physicians

- Eliminate gender-biased language in feedback

- Training and monitoring in milestone achievement process

- Provide implicit bias testing to individuals

Q6: What do you think leaders at medical societies should be doing to ensure that women are safe from sexual harassment at conferences?

- Call for zero tolerance of sexual harassment at conferences

- Clear policy of zero tolerance for harassment, a safe and available reporting process, and sanction/removal of individuals participating in such behavior

- Encourage speaking up about witnessed harassment/derogatory comments

- Provide safe zones for those harassed and task leaders with monitoring for harassment

- Encourage reporting of at-risk situations by confidential, anonymous, and retaliation-free avenues

- Include bystander reporting

- Transparency in complaint handling and outcomes

- Campaigns to address gender/societal stereotypes and harassment

- Real-time feedback on gender bias

- Root cause analysis of harassment incidents

- Provide conference attendees with antiharassment materials and resources

- Combat inaccuracies regarding disparities and workforce concerns in writing, involving an influential senior physician in the process

- Leadership accountability in addressing harassment and gender discrimination/bias

Q7: There is a body of literature-in medicine and beyond-supporting that women are often judged worse than men when their gender is known, but not when their gender is disguised. So what should medical education leaders do to decrease gender-based judgment?

- Training on implicit bias and stereotype threat

- Education on the negative impact of gender stereotypes, schemas and bias

- Objective assessments of trainees with training on recognizing bias in assessments

- Accept varied definitions of gender and allow individualized education

- Blind applications to avoid bias in admissions process

- Recognize and avoid "double bind" (conflicting messaging) in assessments

- Address all trainees with MD as "Dr" to model respect and equity

- Ask publicly, "What would you think if I/she were a man?"

- Consider social-belonging and value-affirmation interventions

- Collect data on bias to drive change

- Blind gender in the review processes to limit bias

- Assess opinions about the rate of bias/stereotype

- Leadership accountability in decreasing bias in all processes

- Ensure evaluations assess the work, not the worker

Q8: How can we get our professional societies to examine inclusion data for women members and address gaps expeditiously?

- Provide a specific path forward through a published process

- Demand medical societies use metrics and analyze inclusion by gender with transparency in all awards, speakers, committees, and leadership roles to stakeholders

- Allow committee membership to change more frequently and invite younger members to apply

- Join leadership and advocate for change by offering solutions

- Societies, schools, and organizations must examine, report, investigate, implement, track, and publish

- Establish benchmarks, set targets, and report with transparency

Workforce gender equity solutions proposed by chat participants were listed and abbreviated to glean important (bulleted list) and recurring (italic) themes.

(as is tradition for journal clubs), the chat provided an opportunity to collect actionable steps for advocacy, implementation, and research on gender-related bias and disparities.

\section{Limitations}

Limitations of this study include those related to implementation of a new strategy using rapidly advancing technology. Article download and share information were not available on the journal websites associated with seven of the eight articles. Even when available (Journal of General Internal Medicine), data did not include information about who downloaded the article. We do not know whether the Pregnancy article was downloaded by health care professionals or interested members of the public, nor can we correlate downloads directly with any individual's participation in the chat. The real-time nature and fluidity of social media also result in the potential for data to change rapidly, hence the short time frame for data collection and validation. Moreover, although the $P W$ chat takes place regularly on Wednesdays from 3:00 to 4:00 pm, Eastern Standard Time, repetition of real-time participant activity measures may be difficult because this chat was preceded by targeted invitations to individuals who were likely to create discussion, participants were limited 
to those with Twitter accounts who self-selected to participate, and measures and patterns of audience engagement on Twitter may have been impacted by time of day, specifically timing during the work day. We cannot account for reasons behind variability in the number of answers proposed for each question (Table 4). It is possible that outcomes were impacted by timing and speed of questions posed (less than 10 minutes each), levels of interest and concern about the issue highlighted by the question, concurrent workload, distraction from the conversation, level of a participant's previous consideration of the topic, and ability of participants to propose and/or share solutions. Due to the short time frame involved (no more than 30 days after the chat), we did not measure other outcomes related to the dissemination of this research such as changes in citations, speaking or writing opportunities, workplace gender equity, or professional credibility related to research on gender equity.

\section{Conclusions}

This study demonstrated that a strategic online social media approach employing a tweet chat could increase the dissemination of the selected research, amplifying the authors' works. Moreover, we were able to drive active discussion about gender equity issues and accumulate potential solutions. Although we focused on gender equity issues, our strategy has widespread potential for accelerating awareness (advocacy) as well as more rapid development and implementation of potential solutions to a variety of problems in medicine today.

\section{Acknowledgments}

The authors wish to thank all the women physicians who participated in the February 2018 summit and who contributed to the social media dissemination that was part of this study. These include Rosalyn Nazarian, MD (Harvard Medical School), Rekha Chandrabrose, MD (University of California, San Diego), Katherine Sharkey, MD, PhD (Brown University), Daleela Dodge, MD (Penn State Health), Allison Larson, MD (Boston University School of Medicine), Carol Marquez, MD (Stanford University), Susan Moeschler, MD (Mayo Clinic), Sasha Shillcutt, MD (University of Nebraska Medical Center), Hansa Bhargava, MD (Children's Health care of Atlanta), Ranna Parekh, MD (American Psychiatric Association), Sarah Diekman, MD (Florida Mechanical and Agricultural University), Robin Schoenthaler, MD (Massachusetts General Hospital), Reem Ghalib, MD (Texas Clinical Research Institute), and Philomena Sante, MD (Northeastern University Health Services). The authors also thank all of our allies who have supported the dissemination of gender equity research on social media and beyond.

\section{Author Disclosure Statements}

No competing financial interests exist.

\section{Supplementary Material}

Supplementary Table S1

\section{References}

1. Freund KM, Raj A, Kaplan SE, et al. Inequities in academic compensation by gender: A follow-up to the National Faculty Survey cohort study. Acad Med 2016;91:1068-1073.
2. Carr PL, Raj A, Kaplan SE, Terrin N, Breeze JL, Freund KM. Gender differences in academic medicine: Retention, rank, and leadership comparisons from the National Faculty Survey. Acad Med 2018;93:1694-1699.

3. Silver JK, Ghalib R, Poorman JA, et al. Analysis of gender equity in leadership of physician-focused medical specialty societies (2008-2017). JAMA Intern Med 2018 [Epub ahead of print]; DOI: 10.1001/jamainternmed.2018.5303.

4. Silver JK, Slocum CS, Bank AM, et al. Where are the women? The underrepresentation of women physicians among recognition award recipients from medical specialty societies. PM R 2017;9:804-815.

5. Boiko JR, Anderson AJM, Gordon RA. Representation of women among academic grand rounds speakers. JAMA Intern Med 2017;177:722-724.

6. Files JA, Mayer AP, Ko MG, et al. Speaker introductions at internal medicine grand rounds: Forms of address reveal gender bias. J Womens Health (Larchmt) 2017;26:413419.

7. Silver JK, Poorman JA, Reilly JM, Spector N, Goldstein $\mathrm{R}$, Zafonte RD. Assessment of women physicians among authors of perspective-type articles published in highimpact pediatric journals. JAMA Network Open 2018;1: e180802.

8. Silver JK, Reilly JM, Gallegos-Kearin V, Poorman JA, Bhatnagar S, Zafonte R. Women physicians are often not visible in newsletters published by the American Academy of Physical Medicine and Rehabilitation. Paper presented at: Annual Assembly of American Academy of Physical Medicine and Rehabilitation; October 25-28, 2018; Orlando, FL.

9. Choo EK. Damned if you do, damned if you don't: Bias in evaluations of female resident physicians. J Grad Med Educ 2017;9:586-587.

10. Ross DA, Boatright D, Nunez-Smith M, Jordan A, Chekroud A, Moore EZ. Differences in words used to describe racial and gender groups in medical student performance evaluations. PLoS One 2017;12:e0181659.

11. Madera JM, Hebl MR, Martin RC. Gender and letters of recommendation for academia: Agentic and communal differences. J Appl Psychol 2009;94:1591-1599.

12. Bickel J. Women in medicine: Evidence that more evidence is insufficient in effecting improvements. Acad Med 2017; 92:274.

13. Hekman DR, Johnson SK, Foo M-D, Yang W. Does diversity-valuing behavior result in diminished performance ratings for non-white and female leaders? Acad Manage J 2017;60:771-797.

14. Shillcutt SK, Silver JK. Social media and advancement of women physicians. N Engl J Med 2018;378:2342-2345.

15. Krause ML, Elrashidi MY, Halvorsen AJ, McDonald FS, Oxentenko AS. Impact of pregnancy and gender on internal medicine resident evaluations: A retrospective cohort study. J Gen Intern Med 2017;32:648-653.

16. Impact of pregnancy and gender on internal medicine resident evaluations: A retrospective cohort study. SpringerLink. Available at: https://link.springer.com/article/10 .1007/s11606-017-4010-5. Published 2017. Accessed July 20, 2018.

17. Who's talking about your research? Altmetrics. Available at: www.altmetric.com Accessed July 20, 2018.

18. The Altmetric details page. Altmetric. Available at: www .altmetric.com/about-our-data/altmetric-details-page. Published 2018. Accessed July 20, 2018. 
19. The donut and Altmetric Attention Score. Altmetric. Available at: www.altmetric.com/about-our-data/the-donut-andscore Accessed July 30, 2018.

20. Glossary. Twitter, Inc. Available at: https://help.twitter .com/en/glossary. Published 2018. Accessed July 20, 2018.

21. About your activity dashboard. Twitter. Available at: https:// help.twitter.com/en/managing-your-account/using-the-tweetactivity-dashboard. Published 2018. Accessed July 23, 2018.

22. Union Metrics (homepage). TrendKite. Available at: https://unionmetrics.com. Published 2018. Accessed July 20, 2018.

23. Madsen TE, Linden JA, Rounds K, et al. Current status of gender and racial/ethnic disparities among academic emergency medicine physicians. Acad Emerg Med 2017; 24:1182-1192.

24. Silver JK, Blauwet CA, Bhatnagar S, et al. Women physicians are underrepresented in recognition awards from the Association of Academic Physiatrists. Am J Phys Med Rehabil 2018;97:34-40.

25. Mueller AS, Jenkins TM, Osborne M, Dayal A, O'Connor DM, Arora VM. Gender differences in attending physicians' feedback to residents: A qualitative analysis. J Grad Med Educ 2017;9:577-585.

26. Bates CK, Jagsi R, Gordon LK, et al. It is time for zero tolerance for sexual harassment in academic medicine. Acad Med 2018;93:163-165.

27. Salles A, Mueller CM, Cohen GL. Exploring the Relationship Between Stereotype Perception and Residents' Well-Being. J Am Coll Surg 2016;222:52-58.

28. Morris ZS, Wooding S, Grant J. The answer is 17 years, what is the question: Understanding time lags in translational research. J R Soc Med 2011;104:510-520.

29. Niehaus WN, Silver JK, Katz MS. The PM\&R journal implements a social media strategy to disseminate research and track alternative metrics in physical medicine and rehabilitation. PM R 2018;10:538-543.

30. Cosco TD. Medical journals, impact and social media: An ecological study of the Twittersphere. CMAJ 2015;187: 1353-1357.

31. Bibliometrics. Oxford University Press, Oxford Living Dictionaries. Available at: https://en.oxforddictionaries.com/ definition/bibliometrics. Published 2018. Accessed July 25, 2018.

32. King MM, Bergstrom CT, Correll SJ, Jacquet J, West JD. Men set their own cites high: Gender and self-citation across fields and over time. arXivorg 2016. https://arxiv .org/abs/1607.00376 Accessed July 20, 2018.

33. Nagendran M, Dimick JB. Disseminating research findings: Preparing for Generation Y. JAMA Surg 2014;149:629-630.

34. Cabrera D, Vartabedian BS, Spinner RJ, Jordan BL, Aase LA, Timimi FK. More than likes and tweets: Creating social media portfolios for academic promotion and tenure. J Grad Med Educ 2017;9:421-425.

35. Evaniew N, Adili AF, Ghert M, et al. The scholarly influence of orthopaedic research according to conventional and alternative metrics: A systematic review. JBJS Rev 2017;5:e5.

36. Mayol J, Dziakova J. Value of social media in advancing surgical research. Br J Surg 2017;104:1753-1755.
37. Kelly BS, Redmond CE, Nason GJ, Healy GM, Horgan NA, Heffernan EJ. The use of Twitter by radiology journals: An analysis of Twitter activity and impact factor. J Am Coll Radiol 2016;13:1391-1396.

38. Kotsenas AL, Aase L, Arce M, et al. The social media DNA of Mayo Clinic-and health care. J Am Coll Radiol 2018;15(1 Pt B):162-166.

39. Bosslet GT, Torke AM, Hickman SE, Terry CL, Helft PR. The patient-doctor relationship and online social networks: Results of a national survey. J Gen Intern Med 2011;26: 1168-1174.

40. Brown J, Ryan C, Harris A. How doctors view and use social media: A national survey. J Med Internet Res 2014; 16:e267.

41. Adilman R, Rajmohan Y, Brooks E, et al. Social media use among physicians and trainees: Results of a national medical oncology physician survey. J Oncol Pract 2016;12: 79-80, e52-e60.

42. Social media fact sheet Pew Research Center. Available at: www.pewinternet.org/fact-sheet/social-media. Published 2018. Accessed July 20, 2018.

43. Raghupathi W, Raghupathi V. Big data analytics in healthcare: Promise and potential. Health Inf Sci Syst 2014;2:3.

44. Widmer RJ, Engler NB, Geske JB, Klarich KW, Timimi FK. An academic healthcare Twitter account: The Mayo Clinic experience. Cyberpsychol Behav Soc Netw 2016;19: 360-366.

45. Choo EK, Ranney ML, Chan TM, et al. Twitter as a tool for communication and knowledge exchange in academic medicine: A guide for skeptics and novices. Med Teach 2015;37:411-416.

46. Glowacki EM, Lazard AJ, Wilcox GB, Mackert M, Bernhardt JM. Identifying the public's concerns and the Centers for Disease Control and Prevention's reactions during a health crisis: An analysis of a Zika live Twitter chat. Am J Infect Control 2016;44:1709-1711.

47. Lazard AJ, Scheinfeld E, Bernhardt JM, Wilcox GB, Suran M. Detecting themes of public concern: A text mining analysis of the Centers for Disease Control and Prevention's Ebola live Twitter chat. Am J Infect Control 2015; 43:1109-1111.

48. Mitchell BG, Russo PL, Otter JA, Kiernan MA, Aveling L. What makes a tweet fly? Analysis of Twitter messaging at four infection control conferences. Infect Control Hosp Epidemiol 2017;38:1271-1276.

49. Chai PR, Ruha AM, Wong KE, et al. The Virtual Toxicology Journal Club: The dissemination and discussion of noteworthy manuscripts using Twitter. J Med Toxicol 2018;14:212-217.

Address correspondence to:

Kelly A Cawcutt, MD, MS

Division of Infectious Diseases University of Nebraska Medical Center 985400 Nebraska Medical Center Omaha, NE 68198

E-mail: kelly.cawcutt@unmc.edu 